\title{
Numerical Simulation on Instability Mechanism of Section Coal Pillar in Shallow Buried Coal Seams
}

\author{
Tielin SHANG*, Yuwei LIU, Yonglu SUO, Jindong WANG, Zhiyi WANG
}

\begin{abstract}
There is abundant coal resource of Jurassic period in Yulin City, and the problem of shallow buried coal seams mining will occur in every mine area. FLAC3D is used to analyze the plastic failure, deformation characteristic, and vertical stress on shallow buried coal seams mining, based on north No. 2 engineering geological conditions of Hongliulin Mining Corporation. In this paper, the results are shown as follows. The plastic failure fields of section coal pillar forming are smaller; the coal seam hosting is shallower. The elastic region of section coal pillar has a relatively large proportion, which is the coal seam first mined. The value of Z-Displacement for the first coal seam is relatively small. However, for the lower coal seam it is relatively big. The value of $X$-Displacement for each coal seam is relatively small. The coal wall of section coal pillar is in a steady state. The coal seam hosting is deeper; the more distant is from coal wall to peak point abutment pressure. The stress concentration factor for the first coal seam is relatively big. The research conclusion reveals instability mechanism of section coal pillar, while coal seams mining, which provides a theoretical basis for designing width vale and optimizing supporting scheme of section coal pillar, has engineering experience application value to other coalmines in Yulin City.
\end{abstract}

Keywords: instability mechanism; numerical simulation; section coal pillar

\section{INTRODUCTION}

The Jurassic coalfield in northern Shaanxi is located in Yulin City and is divided into Shenfu mining area, Yulin mining area, Yuheng mining area and Jingding preprospecting area. The coalfield has a total distribution area of $31600 \mathrm{~km}^{2}$, coal resources of 226.7 billion tons, and cumulative proven reserves of 159.6 billion tons. The deep inclined seam is $1^{\circ}$ to $3^{\circ}$, the geological structure is simple, and the coal seam is stable. The coal seam is relatively shallow, with 1 to 14 minable coal seams, with a total minable thickness of 0.7 to $26.89 \mathrm{~m}$, which is one of the seven largest coalfields in the world [1]. In recent years, as the annual output of various mines was gradually increased and the mining intensity was continued to increase, the coal seam of the lower mining practice has begun, in some areas. The mining of shallow buried coal seams is common in all mining areas. A large number of scholars in China have conducted a lot of research on the stability control of coal pillars in a single section coal pillar and have obtained rich research results. During the mining of the coal seam group, the remaining coal pillars in the upper coal seam will form a stress concentration area at the bottom. When the distance between coal seams is close, it will damage the coal pillars and roadway support in the lower coal seam [2, 3].

Professor Huang Qingxiang used the Ningtiaota minefield in the Shennan mining area in northern Shaanxi as a background. Through physical simulation and numerical calculation, he revealed the breaking law of the interval rock, the distribution law of the concentrated stress of the coal pillar, the overburden, and the surface in the coal seam mining in different coal pillar sections. The law of crack development and the law of surface subsidence have mastered the relationship between the staggered distance of different sections of coal pillar, the stress concentration of coal pillars and the crack evolution of overburden rock [4, 5]. Professor Suo Yonglu used computer numerical simulation and theoretical analysis to conclude that the reasonable layout of coal seam mining roadways in Chenghe Bailiang Xusheng Coal Mine should adopt an internal error of $4-8 \mathrm{~m}$ [6]. Aiming at the rational layout of the mining roadway in the same mining face in the Huojitujing coal seam at the very close distance in Daliuta Coal Mine, Chen Sushe used numerical simulation and field measurement methods to conduct a study on the layout of the double roadway under the coal pillars in the very close distance coal seam with a seam spacing of less than $2 \mathrm{~m}$. Huang Peng took the coal pillar stability of Xiaojihan Coal Mine's goaf section as the research background, and comprehensively used experimental testing, theoretical analysis, on-site monitoring, and numerical simulation [7]. He systematically studied the creep characteristics of damaged coal samples, and put forward the criterion of sudden instability of empty section coal pillars by the stability control method of the section coal pillars [8]. Professor Huang Qingxiang took the mining under the goaf of the very close coal seam in the Huoluowan Coal Mine as the research object, and used physical similarity simulation experiments. The study found that during the compaction stage of the mined-out area, the structure of the collapsed roof of the upper coal seam was activated, showing stepped subsidence, with obvious dynamic load, and having the structural characteristics of "step beam". Periodic "high pressure area" and "low pressure area" appear on the working face [9]. In order to determine the reasonable section coal pillar of Nanliang Mine, Professor Zhang Jie designed plane models and three-dimensional models of different sizes of section coal pillars based on similar simulation experiment principles and conducted the stability study of coal pillars [10]. Li Chunyuan studied the disturbance evolution mechanism of the coal pillars on the floor stress in the overlying section before and after the mining of the underlying coal seam according to the disturbance propagation law of the coal pillars on the floor stress. He calculated and analyzed the disturbance of the mining of the underlying coal seam in the area of the legacy coal pillars [11]. Nowadays, research on the stability of section coal pillars is lacking for the shallow buried coal seams. Therefore, it is very important to study instability mechanism and failure characteristics of section coal pillar for reasonable width and assign position on the shallow 
buried coal seam conditions in the Yulin area, which have important engineering practical value.

Numerical simulation is an important method for coal seam mining practice process. FLAC ${ }^{3 \mathrm{D}}$ is often used to analyze the plastic failure, deformation characteristic, and vertical stress on coal mining process. This paper takes the shallow buried coal seam group in north No. 2 part mining area of Hongliulin coalmine as the engineering practice background. Through computer numerical simulation, the plastic failure range, deformation characteristics, and stress distribution law of coal pillars in each section coal pillars are studied during the mining process of coal seam group. This paper reveals the instability mechanism of the coal pillars in the mining process of coal seam group. It has important theoretical research significance and engineering practical value for the determination of its reasonable width, layout position, and support plan. It provides scientific basis for section coal pillar in shallow buried coal seam group mining area in Yulin area.

\section{ESTABLISHMENT OF FLAC3D SIMULATION MODEL}

\subsection{The Basic Parameters of the Calculation Model}

Shaanxi Coal Group Shaanbei Mining Hongliulin Mining Company is divided into 5 panels in the underground, namely, the South No. 1 Panel, the South No. 2 Panel, the North No. 1 Panel, the North No. 2 Panel and the West No. 1 Panel. The coal-bearing strata are Jurassic. The Yan'an Formation of the Middle System is divided into five coal-bearing sections from bottom to top. Each section contains 1 coal group, numbered 1-5 coal groups, and the coal-bearing seams are $1^{-2}, 2^{-2}$ upper, $2^{-2}, 3^{-1}, 4^{-2}$ upper, 4 $2,4^{-3}$, Coal seams $4^{-4}, 5^{-2}, 5^{-2}, 5^{-3}, 5^{-4}$, of which coals $2^{-2}$, $3^{-1}, 4^{-2}, 4^{-3}, 4^{-4}$, and $5^{-2}$ are available Mining coal seams. The north second panel has a strike length of 2632-3318 m, a dip length of $6000 \mathrm{~m}$, and an area of about $17.8 \mathrm{~km}^{2}$. It is designed to mine $3^{-1}$ coal, $4^{-2}$ coal, and $5^{-2}$ coal. The $3^{-1}$ coal seam is located at the top of the third section of Yan'an Formation, with a minable thickness of $1.80-3.42 \mathrm{~m}$, with an average of $3.03 \mathrm{~m}$. Coal $4^{-2}$ is located at the top of the second section of Yan'an Formation, with a distance of $33.85-60.20 \mathrm{~m}$ above the $3^{-1}$ coal seam, generally $38-44 \mathrm{~m}$, with an average of $43.51 \mathrm{~m}$, and a recoverable thickness of $1.00-4.05 \mathrm{~m}$, with an average of $3.36 \mathrm{~m}$. The $5^{-2}$ coal seam is located at the top of the first section of the Yan'an Formation, with a distance of 11.83 to $43.25 \mathrm{~m}$ above the $4^{-4}$ coal, generally 30 to $38 \mathrm{~m}$, with an average of $30.48 \mathrm{~m}$, a recoverable thickness of 1.00 to 7.95 $\mathrm{m}$, and an average thickness of $4.56 \mathrm{~m}$. The coal mining adopts the long wall mining along the strike method with the downward mining sequence, which is equipped with comprehensive mechanized mining equipment for mining all heights at one time $[12,13]$.

The FLAC3D numerical calculation model is mainly constructed based on borehole 4-HB3 and combined with relevant geological data. The model is designed with 26 layers, from bottom to top: medium-grained sandstone, siltstone, $5^{-2}$ coal, siltstone, ..., mudstone, $4^{-2}$ coal, medium-grained sandstone,..., medium-grained sandstone, mudstone, $3^{-1}$ coal, mudstone, fine-grained sandstone, medium-grained sandstone and siltstone, and other rock layers such as overlying clay, loess, aeolian sand, etc. are far away from the mining coal seam. The top surface of the model is used to apply an equivalent uniform load. The overall model is shown in Fig. 1.

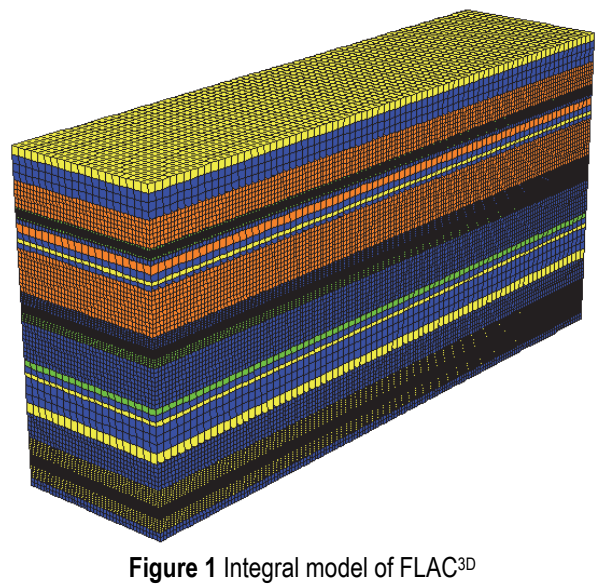

Numerical simulation calculation mainly analyzes the plastic failure range, stress distribution and deformation characteristics of the section coal pillars in the process of coal seam mining. The focus of the simulation calculation is the section coal pillars and the area near the roof and floor, and the distant position is not in the analysis range. Therefore, the thickness of the surrounding rock model is slightly rounded, and the grid cells are divided into unequal divisions $(x \times y \times z)$. The coal seam and its roof and floor cells are densely divided by $1 \times 1 \times 1 \mathrm{~m}$, and the rest are sparser as they are farther from the key research object. The design model has a strike length ( $x$ direction) of $320 \mathrm{~m}$, a tilt length ( $y$ direction) of $80 \mathrm{~m}$, and a height ( $z$ direction) of $157 \mathrm{~m}$. The calculated model has a total of 1188800 zones and 1286587 grid-points.

The model flank is a ball support, which limits its lateral and horizontal movement, and the bottom of the model is fixed to limit its horizontal and vertical displacement [14-17]. The self-weight load of the simulated overburden rock layer on the top of the model is calculated by Eq. (1).

$q=\sum_{i=1}^{n} r_{i} h_{i}$

The upper surface of the model is taken to underground at $82.15 \mathrm{~m}$, and the average density is calculated according to the weighted average of 2300 $\mathrm{m}^{3} / \mathrm{kg}$, then the pressure at the top of the model is $q=2300$ $\times 9.8 \times 82.15=1.852 \mathrm{MPa}$.

\subsection{Selection of Mechanical Parameters}

Rock is generally brittle, and its mechanical properties are expressed as compressive strength greater than shear strength, which is also greater than tensile strength. In the process of coal mining, the sedimentary rock mass undergoes elastic, plastic deformation and plastic failure under the action of unbalanced external forces, and the plastic failure is usually manifested as tensile failure and shear failure. The ideal Mohr-Coulomb plastic yield criterion (Mohr-Coulomb plastic model) is used for simulation calculation of coal and rock materials, and the strain mode is set to large strain deformation. Because the 
engineering geology surrounding rock mass is a heterogeneous body with weak surfaces such as bedding, joints, and fractures, its mechanical parameters are much smaller than the rock mass mechanics specimens [18-20].
Referring to the specific engineering geology report and related rock mechanics experimental results, the rock mass mechanical parameters used in the simulation calculation are shown in Tab. 1.

Table 1 Coal crag mechanics parameter

\begin{tabular}{|c|c|c|c|c|c|c|}
\hline Lithology & $\begin{array}{l}\text { Bulk modulus } \\
\text { / GPa }\end{array}$ & $\begin{array}{l}\text { Shear modulus } \\
/ \mathrm{GPa}\end{array}$ & $\begin{array}{c}\text { Cohesive force } \\
/ \mathrm{MPa}\end{array}$ & $\begin{array}{c}\text { Internal friction angle } \\
/{ }^{\circ}\end{array}$ & $\begin{array}{c}\text { Tensile strength } \\
/ \mathrm{MPa}\end{array}$ & $\begin{array}{l}\text { Density } \\
/ \mathrm{kg} / \mathrm{m}^{3}\end{array}$ \\
\hline Siltstone & 1.8 & 1.3 & 1.6 & 35 & 1.1 & 2340 \\
\hline coal & 1.4 & 1 & 1.4 & 30 & 0.9 & 1270 \\
\hline Mudstone & 1.3 & 1.1 & 1.3 & 35 & 0.85 & 2450 \\
\hline Fine-grained sandstone & 1.6 & 1.2 & 1.8 & 36 & 1.2 & 2520 \\
\hline Medium-grained sandstone & 2.5 & 1.6 & 2 & 37 & 1.3 & 2210 \\
\hline
\end{tabular}

\subsection{Model Excavation Design}

Considering that FLAC is gradual in time, the corresponding calculation steps in this article imply the time factor, which has a certain corresponding relationship with physical time. The more calculation steps, the corresponding time is longer, and the deformation of the model is greater. In FLAC ${ }^{3 \mathrm{D}}$, the calculation steps required to reach the problem can be controlled by the program or the user. In order to simulate the time effect of excavation, the process of section coal pillar deformation and failure during the downward mining of coal seams is reproduced. In this numerical simulation calculation, the number of calculation steps is determined according to the actual time of each coal seam mining design. This numerical simulation is performed at 3000 time steps.

In the process of coal seam mining, the coal pillars of the working face section are designed according to $20 \mathrm{~m}$. Because the coal seams of $3^{-1}$ coal, $4^{-2}$ coal and $5^{-2}$ coal are separated by a large distance, the positions are arranged in overlap, and $20 \mathrm{~m}$ boundary coal pillars are left on both sides. First, excavate the coal bodies on both sides of the coal pillars in the $3^{-1}$ coal section, after 3000 time steps of calculation. Then carry out the excavation of the coal bodies on both sides of the section coal pillars in the $4^{-2}$ coal, after 3000 time steps of calculation. Finally, the excavation of the coal bodies on both sides of the section coal pillars in the $5^{-2}$ coal was carried out, and the calculation was carried out at 3000 time steps. After the excavation of each coal seam is completed, the plastic failure range, displacement and deformation laws, and stress distribution characteristics of the section coal pillars and surrounding rock masses are analyzed.

\section{ANALYSIS OF SIMULATION RESULTS 3.1 Plastic Failure Range}

After the completion of $3^{-1}$ coal mining, the plastic failure state of the section coal pillars and nearby coal and rock masses is shown in Fig. 2a. After $4^{-2}$ coal mining is completed, the plastic failure state of the section coal pillars and nearby coal and rock masses is shown in Fig. 2b. After the $5^{-2}$ coal mining is completed, the plastic failure state of the section coal pillar and the nearby coal rock mass is shown in Fig. 2c.

It can be seen from Fig. 2 that after the mining of each coal seam, the section coal pillars have different levels of plastic failure, and the plastic failure is gradually developed from the outside to the inside. The plastic failure depth of the section coal pillars in the $3^{-1}$ coal is $3 \mathrm{~m}$, with a total of about $6 \mathrm{~m}$ on both sides. The plastic failure depth of the section coal pillars in the $4^{-2}$ coal is $4 \mathrm{~m}$, with a total of about $8 \mathrm{~m}$ on both sides. The plastic failure depth of section coal pillars in the $5^{-2}$ coal is $6 \mathrm{~m}$, with a total of about $12 \mathrm{~m}$ on both sides.

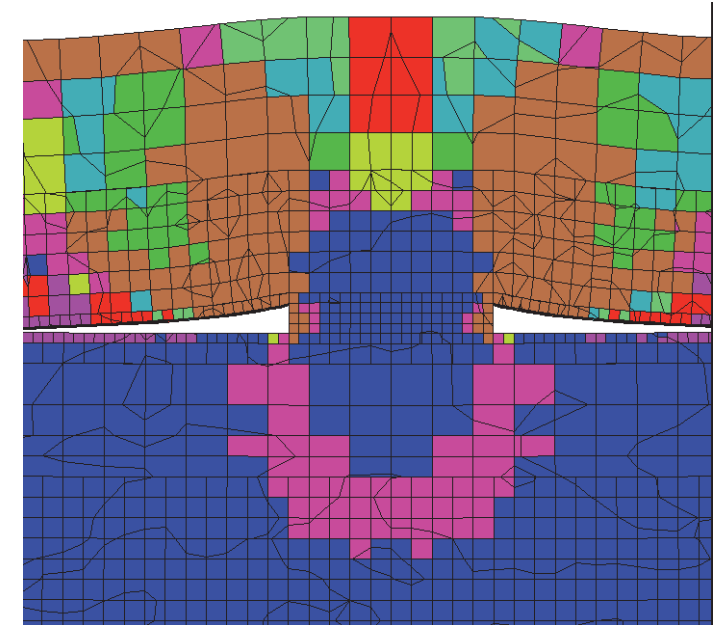

(a) Plastic failure state of coal and rock mass near section coal pillars after $3^{-1}$ coal mining

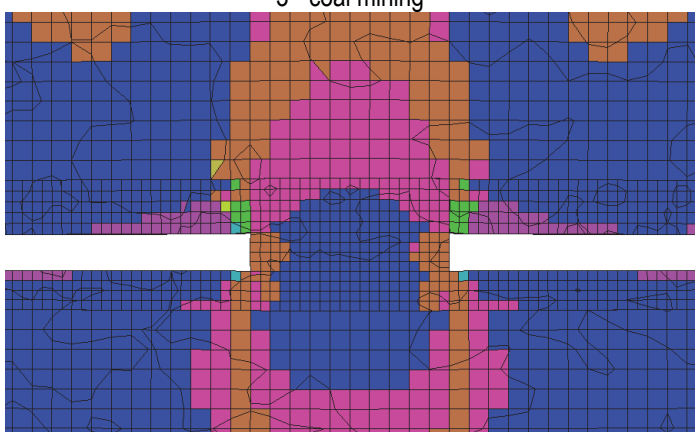

(b) Plastic failure state of coal and rock mass near section coal pillars after $4^{-2}$ coal mining

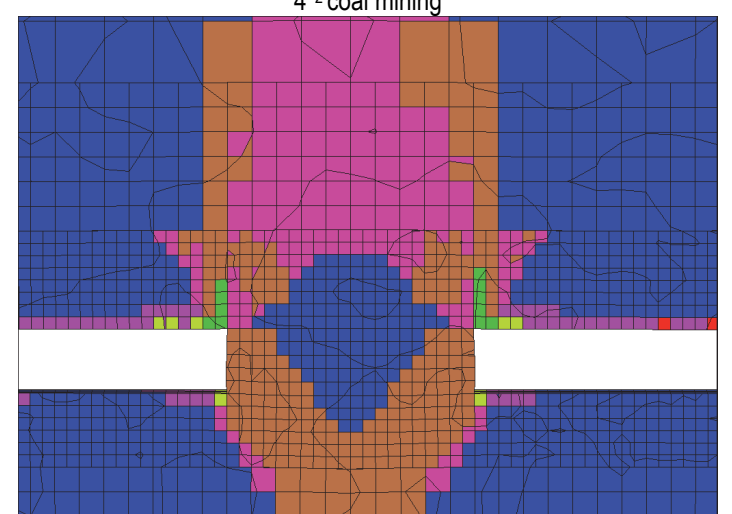

(c) Plastic failure state of coal and rock mass near coal pillar after 5-2 coal mining

Figure 2 Plastic characteristic of section coal pillar after mining 
The extent of plastic failure of the section coal pillars can be seen, and the middle of the section coal pillars are all elastic regions (elastic cores) where no plastic failure has occurred. And in the case of section coal pillars in the $20 \mathrm{~m}$, the shallower the coal seam is, the larger the elastic zone will be. Fig. 2a shows that the plastic failure and caving movement of the overburden rock layers such as the direct roof and old roof of the $3^{-1}$ coal all reach the surface. Fig. $2 \mathrm{~b}$ and Fig. $2 \mathrm{c}$ show that the collapsed state of the roof of $4^{-2}$ coal and $5^{-2}$ coal is very different from that of $3^{-1}$ coal. The loose bodies such as overlying aeolian sand, loess, and red soil, are easily integrated destroyed, forming a cut-off step sinking, and it is not easy to form a threezone collapse form. The lower sandstone-like bedrock has relatively large mechanical parameters, strong integrity, not easy to break, which can prevent further collapse of the overlying loose body. The collapsed state of the roof is similar to that of conventional rock formations, which will not form an overall cut-off situation. There is a certain range of undamaged rock mass above the coal pillars of each section coal pillar, indicating that the in-situ stress of the rock above it is not entirely borne by the section coal pillars. A special structure must be formed on both sides of the section coal pillar to support the overburden rock mass together with the section coal pillar, and the ground stress has been transferred to the coal pillar floor rock.

\subsection{Displacement and Deformation Laws}

After the coal seam is excavated, the destruction and deformation of the coal pillars are in a dynamic process of change. The history function of FLAC ${ }^{3 \mathrm{D}}$ is used to record the dynamic changes of the displacement of each position in the whole process. In the process of $3^{-1}$ coal mining, displacement monitoring points are set up on both sides of the coal pillars of the coal body roof and roadside, respectively ( $x=150, y=4, z=129)$, recorded as history $i d=1$. In addition, $(x=170, y=4, z=129)$, recorded as history $i d=2$. Monitor the vertical displacement $(x=150$, $y=4, z=127.5$ ) and record it as history $i d=3$. Moreover, $(x=170, y=4, z=127.5)$, recorded as history $i d=4$. Monitor the amount of displacement in the horizontal direction. During the mining of $4^{-2}$ coal and $5^{-2}$ coal, monitoring points were set up on both sides of the section coal pillar in the same way. After the calculation process of 3000 time steps, the $3^{-1}$ coal mining process, the vertical displacement of the section coal pillar with time steps change curve is shown in Fig. 3. The vertical displacement curve of $4^{-2}$ coal and $5^{-2}$ coal is roughly the same as that of $3^{-1}$ coal. The figure is omitted. The time-step change curve of the horizontal displacement of the $4^{-2}$ coal road ledge is shown in Fig. 4. The horizontal displacement curves of the $3^{-1}$ coal and the $5^{-2}$ coal are roughly the same as the $4^{-2}$ coal, and the figure is omitted.

It can be read from Fig. 3 that after 3000 time steps, the vertical displacements of the two top corners of the section coal pillars in the $3^{-1}$ coal are $0.06692 \mathrm{~m}$ and $0.06626 \mathrm{~m}$, respectively. The trend of change is fast first and then slow, gradually starting from about 4800 o'clock, and the rate of decline becomes stable. The vertical displacements of the two top corners of section coal pillars in the $4^{-2}$ coal and $5^{-2}$ coal are larger than those of $3^{-1}$ coal, reaching about $0.13 \mathrm{~m}$ and $0.2 \mathrm{~m}$ respectively. The vertical displacement only has a smaller value for $3^{-1}$ coal, and a larger value for $4^{-2}$ coal and $5^{-2}$ coal. This shows that the vertical stress of the coal pillars in the lower section coal pillar is relatively large, and full consideration should be given to the engineering design of the support scheme.

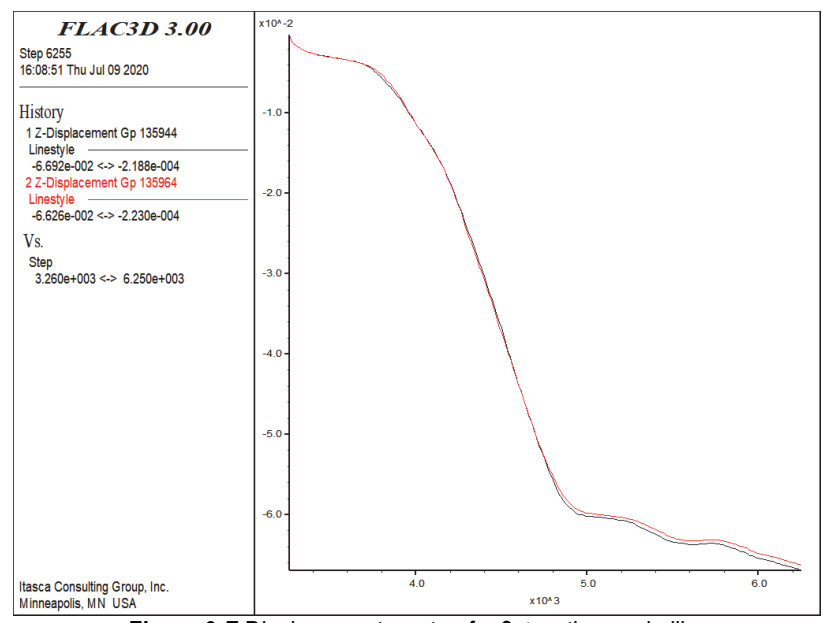

Figure 3 Z-Displacement vs step for $3^{-1}$ section coal pillar

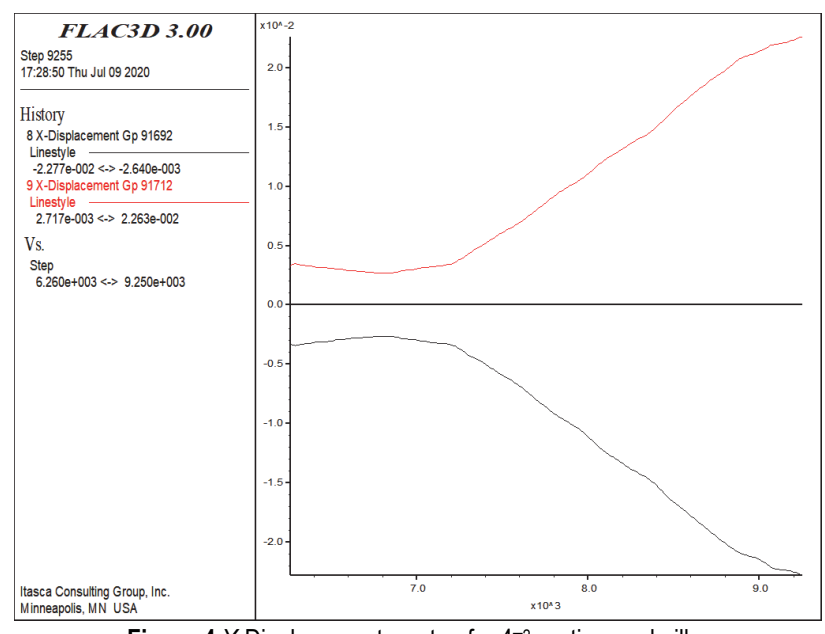

Figure $4 X$-Displacement vs step for $4^{-2}$ section coal pillar

It can be read from Fig. 4 that after 3000 time steps, the horizontal displacement values of the two sides of the section coal pillars in the $4^{-2}$ coal are $0.02277 \mathrm{~m}$ and $0.02263 \mathrm{~m}$, respectively. The horizontal displacement of the two sides of section coal pillars in the $3^{-1}$ coal is about $0.005 \mathrm{~m}$, and the horizontal displacement of the two sides of the section coal pillars in the $5^{-2}$ coal is about $0.09 \mathrm{~m}$. The horizontal displacement value of each coal seam is not large, and the stability of the section coal pillar is better. This shows that under such shallow geological conditions, the first coal seam in the upper part has collapsed due to the overburden rock, and the ground stress is released. The horizontal force of the section coal pillars is small, and the phenomenon of flaking is not easy to occur on both sides [16-18]. In this paper, the selection of support design can be reasonably optimized.

\subsection{The Distribution of Supporting Stress}

After each buried coal seam in the coal seam group is completed, the characteristic form of the section coal pillar support (vertical) stress distribution is basically similar, and stress concentration occurs on the two sides of the 
section coal pillar. There is a certain range of in-situ stress (elastic core) area inside it [21, 22], but the magnitude and concentration of stress are different. Among them, the vertical stress (SZZ) distribution characteristic cloud diagram after the completion of $4^{-2}$ coal mining is shown in Fig. 5.

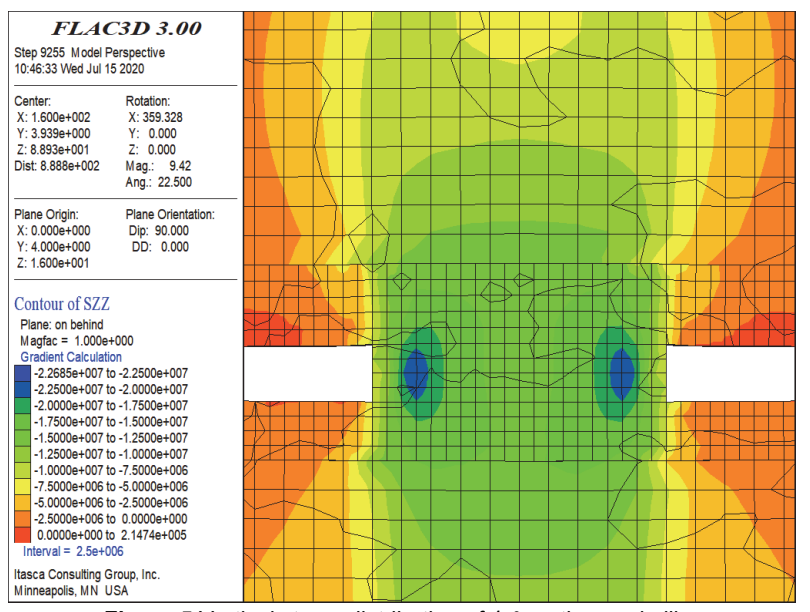

Figure 5 Vertical stress distribution of $4^{-2}$ section coal pillar

In order to further analyze the specific numerical value and distribution law of the supporting stress after mining in each coal seam, this paper uses the log function of FLAC ${ }^{3 \mathrm{D}}$ to call out the specific numerical value of the zone supporting (vertical) stress at the same height in the $x$ direction of the coal pillar in the $20 \mathrm{~m}$ section of the model, $\left(3^{-1}\right.$ Coal $x=150,170 y=4,5 z=127,128.4^{-2} \operatorname{coal} x=$ $150,170 y=4,5 z=84.5,85.5$, and $5^{-2}$ coal $x=150,170$ $y=4,5 z=13.5,14.5)$. This paper draws the curve of supporting stress with different positions of the coal pillars in the section as shown in Fig. 6.

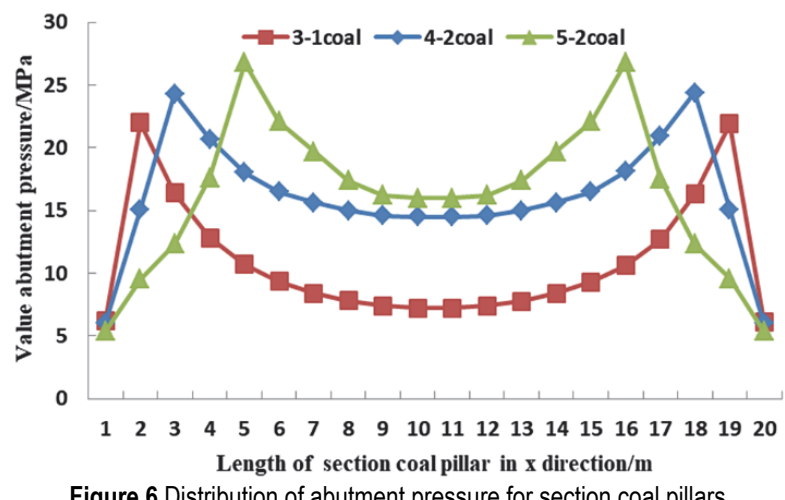

Figure 6 Distribution of abutment pressure for section coal pillars

It can be seen from Fig. 6 that there is a certain stress concentration phenomenon at different depths of the two sides of the coal pillars in each section coal pillar of the coal seam group. The stress peaks of coal $3^{-1}$, coal $4^{-2}$ and coal $5^{-2}$ appear at depths of $2 \mathrm{~m}, 3 \mathrm{~m}$, and $5 \mathrm{~m}$, respectively. The depth of the coal seam is greater, the peak stress is farther away from the coal pillar and coal wall. It shows that for coal seams mining, the buried depth is larger, and the size of the section coal pillar should be increased reasonably. The coal pillar stress concentration coefficients of $3^{-1}$ coal, $4^{-2}$ coal, and $5^{-2}$ coal section are $3.05,1.68$, and 1.675 respectively. The values of $4^{-2}$ coal and $5^{-2}$ coal are the same. However, the value of $3^{-1}$ coal is larger. The reason is related to the special roof structure of the shallow buried coal seam. The size of the section coal pillars can be appropriately reduced. However, the support strength should be increased. The supporting stresses at the edges of coal pillars are $6.17 \mathrm{MPa}, 6 \mathrm{MPa}$, and $5.36 \mathrm{MPa}$, respectively. The supporting stress values at the edges of the coal pillars are similar, indicating that the edge of the coal pillars in the section will not be broken.

\section{CONCLUSION}

The following conclusions can be drawn by analyzing the plastic failure characteristics in the mining process of coal seams, the displacement and deformation of the section coal pillars and coal walls, and the distribution of supporting pressure in the above chapters. For mining of shallow buried coal seams in Yulin area, the coal seam is deeper; the plastic failure area will be larger. During the mining process of the first coal seam, a "step beam" will be formed, and will form a hinged structure with the upper strata of the section coal pillar. On the one hand, this structure will produce obvious stress concentration at the edge of the coal wall, and on the other hand, it will be shared with the section coal pillar, and support the gravity of the overburden rock. Affected by this structure, the elastic area where the coal pillars of the first section coal pillar did not undergo plastic failure is relatively large, and there is a certain size optimization space for the width of the coal pillars. During the mining of shallow buried coal seams, the vertical displacement of the coal pillar roof in the first section coal pillar is small, and the vertical displacement of the lower coal seam is relatively large. When designing the transportation (return air) roadway support plan, it is necessary to strengthen the roof support strength. The horizontal displacement value of coal pillar and coal wall in each section coal pillar is not large. The stability of the coal walls on both sides of the coal pillars in the section is good, and the phenomenon of chipping is not easy to occur. The selection of the support design scheme can be reasonably optimized. The stress concentration phenomenon exists on both sides of the coal pillars of each section coal pillar in the coal seam group, and the value is about $6 \mathrm{MPa}$. Although plastic failure has occurred, it still has a certain supporting strength and not chip. The depth of the coal seam is greater; the peak stress is farther away from the coal wall of the coal pillar. The buried depth is greater, the size of section coal pillar should be increased reasonably. The coal pillar support stress concentration factor in the first section coal pillar is relatively large, and the roof support strength of the roadway at both sides of the section coal pillar should be increased. The numerical simulation conclusion need to be further improved through laboratory simulation of similar materials and monitoring or forecasting of engineering practice.

\section{Acknowledgments}

This work was supported by the National Natural Science Foundation of China (Grant No.52064047); Shaanxi Province Science and Technology Plan Project (Grant No. 2020SF-418); Yulin University Doctoral Research Startup Fund Project (Grant No. 17GK06). 


\section{REFERENCES}

[1] Mu, L.-Y. (2014). Research on the Hydrogeological Characteristics and the Hydrogeological Element divided of Jurassic Coalfield in Northern Shaanxi Province. Doctoral Thesis, Xi'an: Xi'an University of Science and Technology.

[2] Zhang, B.-S., Yang, S.-S., Kang, L.-X. et al. (2008). Discussion on method for determining reasonable position of roadway for ultraclose multi-seam. Chinese Journal of Rock Mechanics and Engineering, 27(1), 97-101.

[3] Zhang, W., Zhang, D.-S., Chen, J.-B. et al. (2012) Determining the optimum gateway location for extremely close coal seams. Journal of China University of Mining \& Technology, 41(2), 183-187.

[4] Huang, Q. \& Du, J. (2018). Coupling control of pillar stress and surface cracks in shallow buried coal seam group mining. Journal of China Coal Society, 43(3), 591-598.

[5] Huang, Q., Du, J., \& Liu, Y.-C. (2016). Study on section coal pillar of group mining in shallow buried coal seams. Journal of Xi'an University of Science and Technology, 36(1), 19-23.

[6] Suo, Y.-L.,Shang, T.-L.,Zheng, Y. et al. (2013). Numerical simulation on rational location of roadways at lower seam for ultra-close multiple seam mining. Journal of China Coal Society, 38(s2), 277-282.

[7] Chen, S. \& Zhu, W. (2016). Study on double-roadway layout under section coal pillar of ultra-close upper coal seams in Huojitu mine. Journal of Mining \& Safety Engineering, 33(3), 467-474.

[8] Huang, P. (2018). Study on the Creep Damage Mechanism of Coal Petrography and Gob-side Coal Pillar Stability. Doctoral Thesis, Xuzhou: China University of Mining and Technology.

[9] Huang, Q., He, Y., Luo, L. et al. (2018). Study on the active structure of caved roof and support resistance in shallow buried and ultra-close coal seams mining. Journal of Mining \& Safety Engineering, 35(3), 561-566.

[10] Zhang, J., Huo, J., Wang, B.-H. et al. (2016). Experimental Analysis on Section Coal Pillar Stability in Shallowburied Seam and Its Application. Mining Safety \& Environmental Protection, 43(1), 30-33.

[11] Li, C., Wang, H., \& Shi, Y. (2020). Study on disturbing influence of overlying remaining coal pillars on underlying coal seam mining. Coal Science and Technology, 48(3), 232239.

[12] Li, H.-J. (2019). Study on the Development Characteristics of Overburden Water Flowing Fracture Zone in Shallow buried coal seam Group of Hongliulin Coal Mine. Doctoral Thesis, Xi'an: Xi'an University of Science and Technology.

[13] Li, J.-H. (2019). Study on Overburden Breakage Law and Mine Pressure Law of Multi-seam Mining in Hongliulin Coal Mine. Doctoral Thesis, Xi'an: Xi'an University of Science and Technology.

[14] Peng, W.-B. (2007). Practical course of FLAC ${ }^{3 D}$. Beijing: Machine and industry press, 81-147.

[15] Shang, T.-L. (2017). Study on Structure Characteristics and Movement Laws of Overlying Strata under Permafrost Layer in Steeply Dipping Seams Mining. Doctoral Thesis, Xi'an: Xi'an University of Science and Technology.

[16] Shang, T.-L., Suo, Y.-L., \&Wie, Y.-C. (2018). Numerical Simulation on Size Optimization of Section Coal Pillar for Coalseam No.3-1 in Hongliulin Coal Mine. Coal Technology, 37(9), 20-23

[17] Shang, T.-L., Suo, Y.-L., \& Wie, Y.-C. (2018). Study on Size Optimization of Section Coal Pillar for Large Height Mining Face in Shallow Coalseam. Journal of Yulin City University, 28(6), 6-10.

[18] Cai, M.-F.,He, M.-C., \& Liu, D.-Y. (2007). Rock mechanics and engineering. Beijing: Science Press, 31-73.
[19] Xu, Y.-X. (2008). Coal mining. Xuzhou: China University of Mining and Technology Press, 17-210. https://doi.org/10.1016/S1006-1266(07)60074-1

[20] Qian, M.-G. \& Shi, P.-W. (2003). Mining pressure and strata control. Xuzhou: China University of Mining and Technology Press, 76-104.

[21] Han C.-Q., Zhang K.-Z., Xu X.-B. et al. (2007). Study on Failure Regularity and Reasonable Dimension of District Sublevel Small Coal Pillar. Journal of Mining \& Safety Engineering, 24(3), 370-373.

[22] Fang, G., Liu, Y., \& Li, A. (2019). Stability Evaluation of Working Face Coal Pillar in Shallow of Shenfu Mine District. Coal Mining Technology, 24(1), 56-61.

\section{Contact information:}

\section{Tielin SHANG}

(Corresponding author)

School of Energy Engineering,

Yulin University,

Shaanxi Yulin 719000, China

E-mail: shangtielin@163.com

Yuwei LIU

School of Civil Engineering,

Zhengzhou University of Technology,

Zhengzhou 450044, China

Yonglu SUO

College of Energy Engineering

Xi'an University of Science and Technology,

Shaanxi Xi'an 710054, China

\section{Jindong WANG}

School of Energy Engineering,

Yulin University,

Shaanxi Yulin 719000, China

\section{Zhiyi WANG}

School of Energy Engineering,

Yulin University,

Shaanxi Yulin 719000, China 